Arq. Bras. Med. Vet. Zootec., v.61, n.6, p.1463-1467, 2009

\title{
Comunicação
}

[Communication]

\section{Ocorrência e variação populacional de Carcinops troglodites em uma granja avícola, em Pelotas, RS}

\author{
[Occurrence and range of population of Carcinops troglodites in a poultry farm in Pelotas, RS]
}

D.M. Pinto, P.B. Ribeiro

Departamento de Microbiologia e Parasitologia - IB-UFPel

96010-900 - Pelotas, RS

O confinamento de animais com o propósito de aumentar a produção fez com que algumas espécies de artrópodes passassem a viver sinantropicamente. Tais espécies apresentam grande importância médica e veterinária pelo fato de algumas delas serem vetores de patógenos (Francisco, 1996).

Dentre as espécies que ocorrem no agroecossistema de aviários, os histerídeos predadores, como Carcinops troglodites (Coleoptera), merecem destaque. Acredita-se que a importância de $C$. troglodites seja equivalente à da espécie Carcinops pumilio, que ocorre nos EUA e que é considerada muito eficiente na redução da população de Musca domestica, devido à alta capacidade predatória, distribuição no esterco e abundância em aviários (Axtell, 1986).

C. troglodites ocorre em áreas tropicais, e cada indivíduo adulto pode consumir cerca de 40 ovos de Chrysomya putoria por dia (Gianizella, 2000). Essa espécie também é mencionada por Berti Filho et al. (1989) e por Mariconi et al. (1999) como predadora de $M$. domestica. Este trabalho teve o objetivo de verificar a ocorrência e a flutuação populacional de C. troglodites.

O estudo foi realizado em um aviário experimental, durante o período de abril de 2002 a março de 2003. A coleta dos insetos foi realizada por meio de dois métodos: (1) armadilha do tipo tubo ou de Arends (Safrit e Axtell, 1984), que consiste em um tubo de polivinilcloreto $(\mathrm{PVC})(3,8 \mathrm{~cm}$ de diâmetro $\times$
$23 \mathrm{~cm}$ de comprimento), contendo em seu interior papel corrugado, colocado de forma que as ondulações fiquem dispostas em sentido longitudinal ao tubo, e (2) armadilha do tipo sanduíche (Safrit e Axtell, 1984), constituída por caixas de madeira $(20 \mathrm{~cm}$ de comprimento $\times$ $15 \mathrm{~cm}$ de largura $\times 8 \mathrm{~cm}$ de altura), com tampa e duas aberturas de $1 \mathrm{~cm}$ no sentido longitudinal, junto à base da caixa, para facilitar a entrada dos insetos, e, no interior, papel corrugado, de modo que a preencha totalmente.

Foram instaladas 16 armadilhas, em grupos de quatro, em quatro locais diferentes do galpão. Cada grupo foi composto por duas armadilhas do tipo sanduíche e duas armadilhas do tipo tubo. As armadilhas foram colocadas sobre a cama (maravalha), dispostas lado a lado, equidistantes $30 \mathrm{~cm}$ umas das outras.

Foram feitas coletas semanais, e o conteúdo de cada armadilha foi colocado em um recipiente plástico com tampa, devidamente identificado, com o auxílio de um funil de alumínio. Nas avaliações, o papel do interior das armadilhas era substituído por um novo, e os insetos capturados eram levados para o laboratório para triagem, identificação e contagem. Os dados climatológicos foram fornecidos pela Estação Climatológica do conjunto Agrotécnico Visconde da Graça, próximo ao local onde se realizou o trabalho.

Os resultados foram submetidos à análise de regressão polinomial, utilizando-se o programa estatístico SANEST (Zonta e Machado, 1984). 
Durante o período experimental, foram capturados 45.764 artrópodes pertencentes às classes Insecta e Arachnida. A classe Insecta

representou 96,6\%, do total de artrópodes capturados (Tab. 1).

Tabela 1. Frequência das classes, ordens e famílias de artrópodes capturadas em galpão de aves poedeiras, no período de abril de 2002 a março de 2003, em Pelotas, RS

\begin{tabular}{lcc}
\hline Classe & Frequência absoluta & Frequência relativa (\%) \\
\hline Insecta & 44.228 & 96,64 \\
Arachnida & 1.536 & 3,36 \\
\hline Total & 45.764 & 100,00 \\
\hline Ordem & Frequência absoluta & Frequência relativa (\%) \\
\hline Coleoptera & 43.945 & 96,03 \\
Dermaptera & 264 & 0,58 \\
Diptera & 19 & 0,04 \\
Pseudoscopionida & 1.536 & 3,36 \\
\hline Total & 45.764 & 100,00 \\
\hline Família & Frequência absoluta & Frequência relativa (\%) \\
\hline Tenebrionidae & 41.617 & 94,70 \\
Histeridae & 795 & 1,81 \\
Ptinidae & 367 & 0,84 \\
Carabidae & 1.166 & 2,65 \\
\hline Total & 43.945 & 100,00 \\
\hline
\end{tabular}

A classe Insecta foi representada pelas ordens Coleoptera, Dermaptera e Diptera. A ordem Coleoptera foi a mais representativa, 96,0\% dos insetos capturados. Das famílias de Coleoptera, Histeridae foi a terceira mais abundante com 1,8\% (Tab. 1). Bicho (2001), no mesmo aviário, ao utilizar armadilhas tipo tubo e coletar fezes acumuladas, obteve maior abundância da família Histeridae, com 53,5\% dos coleópteros coletados. Aagensen (1988) e Bruno et al. (1993), em aviários de diversos municípios de São Paulo, também verificaram ser a família Histeridae a mais abundante, $36,1 \%$ e $39 \%$, respectivamente.
Segundo Geetha Bai e Sankaran (1977), as larvas de histerídeos são eficientes predadores de muscoides, sendo bastante promissores no controle biológico de moscas. Dos histerídeos capturados, Carcinops troglodytes ocorreu durante 10 dos 12 meses de coletas, apresentando seu acme populacional no mês de fevereiro (188), sendo este mês o de média de temperatura mais alta $\left(24,7^{\circ} \mathrm{C}\right)$. O menor índice de coleta ocorreu nos meses de maio e setembro. Nos meses de abril e julho, não houve captura (Tab. 2).

Tabela 2. Ocorrência mensal de Carcinops troglodytes, capturados em galpão de aves poedeiras, no período de abril de 2002 a março de 2003, em Pelotas, RS

\begin{tabular}{cccccccccccccc} 
Abr & Mai & Jun & Jul & Ago & Set & Out & Nov & Dez & Jan & Fev & Mar & Total \\
\hline- & 1 & 2 & - & 2 & 1 & 21 & 22 & 126 & 54 & 188 & 119 & 536 \\
\hline
\end{tabular}


$\mathrm{Na}$ Fig. 1, pode-se observar que a temperatura média mensal variou de $13,8^{\circ} \mathrm{C}$ em setembro, a $24,7^{\circ} \mathrm{C}$, em fevereiro, e a precipitação pluviométrica acumulada mensal oscilou de $2,63 \mathrm{~mm}$ em janeiro, a $321,57 \mathrm{~mm}$, em abril.

A flutuação populacional de C. troglodytes capturada no período pode ser observada na Fig. 2.

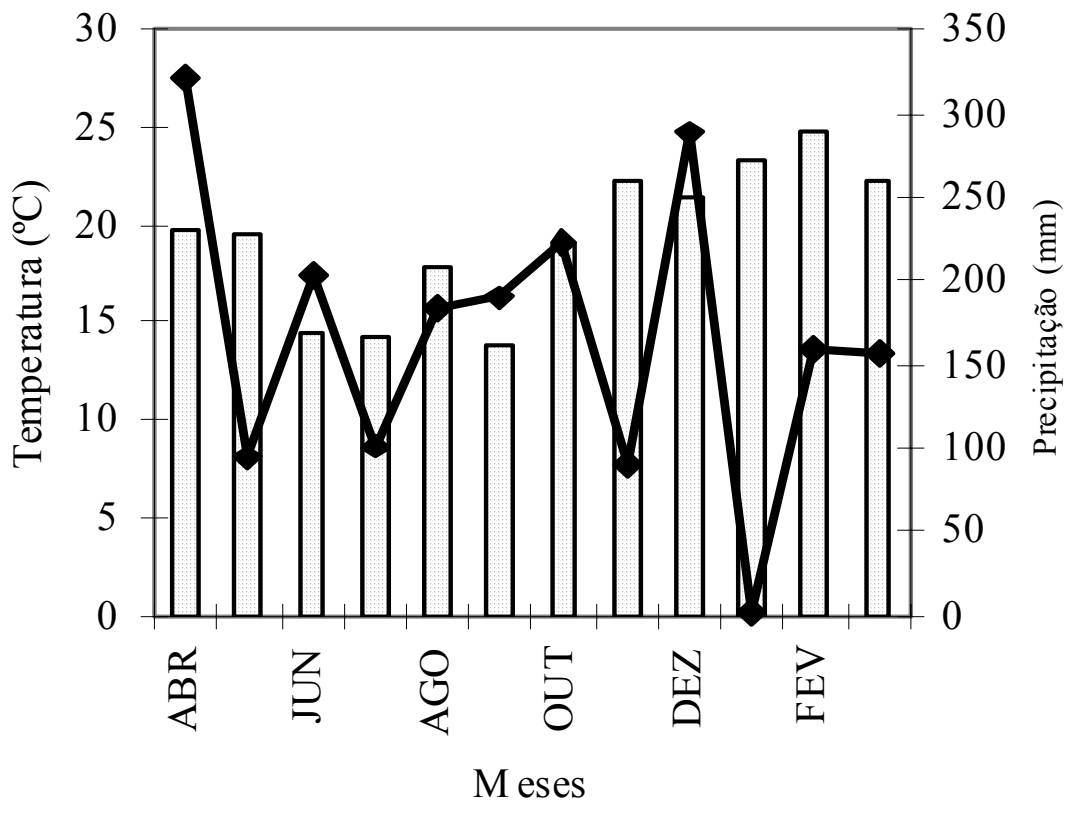

\section{Temperatura -Preciptação Pluviométrica}

Figura 1. Temperatura média mensal e precipitação pluviométrica no período de abril de 2002 a março de 2003, em Pelotas, RS.

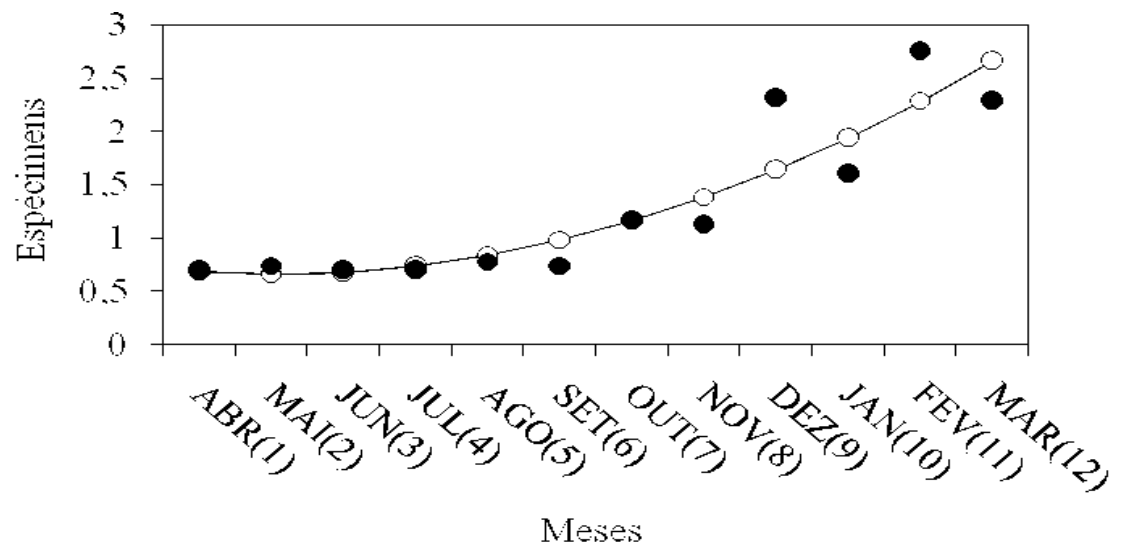

- 02/03 (Medias Observadas) -0-02/03 (Medias Ajustaclas)

Figura 2. Oscilação populacional de Carcinops troglodytes em granja avícola, no período de abril de 2002 a março de 2003, em Pelotas, RS. 
Estes resultados diferem dos obtidos por Bicho (2001), que, ao avaliar a população de artrópodes, também em Pelotas, em excrementos de aves poedeiras e com o uso de armadilha tipo tubo, assinalou essa espécie como a mais abundante, ocorrendo nos 12 meses de coleta, com 6.444 espécimens capturados, representando $51,8 \%$ dos exemplares da ordem.

Aagensen (1988) e Bruno et al. (1993), ao coletarem coleópteros em diversas granjas avícolas em municípios do Estado de São Paulo, afirmaram que $C$. troglodytes foi a espécie mais abundante de captura.

Gianizella e Prado (1998), ao realizarem um levantamento dos histerídeos em uma granja em
Monte Mor, SP, capturaram 19.668 exemplares, sendo a espécie $C$. troglodytes representada por $33 \%$ das sete espécies encontradas.

Segundo Legner e Olton (1970), C. troglodytes também foi encontrado em excremento de aves na Costa Rica e em Porto Rico.

Conclui-se que as condições ambientais do local onde foi realizado o experimento favorecem a ocorrência de $C$. troglodytes, sugerindo o potencial dessa espécie como agente de controle biológico em aviários.

Palavras-chave: aviário, Coleoptera, Histeridae, ocorrência

\begin{abstract}
To evaluate the occurrence and range of population of Carcinops troglodytes, two monitoring methods were used: trap of the type tube and the type sandwich. The experiment took place in a 12-month period. In that period, 536 specimens of $C$. troglodites were captured, being the period of larger occurrence in February (188) and the smallest collection index recorded in May and September (1). The coleopteron presented a variation of the population density throughout the year, being the highest capture averages obtained in the months with higher mean temperatures.
\end{abstract}

Keywords: aviary, Coleoptera, Histeridae, monitoring

\section{REFERÊNCIAS BIBLIOGRÁFICAS}

AAGESEN, T.L. Artrópodes associados a excrementos em aviários. 1988. 38f. Dissertação (Mestrado em Entomologia) - Escola Superior de Agricultura Luiz de Queiroz, Universidade de São Paulo, Piracicaba, SP.

AXTELL, R.C. Fly management in poultry production: cultural, biological, and chemical. Poult. Sci., v.65, p.657-667, 1986.

BERTI FILHO, E.; COSTA, V.A.; AAGEESEN, T.L. Occurrence of natural enemies of Musca domestica L. (Diptera: Muscidae) in poultry areas of Bastos, State of São Paulo, Brazil. Rev. Agric., v.64, p.8-9, 1989.

BICHO, C.L. Comunidade de artrópodes e flutuação populacional circanual de dipteros $e$ coleópteros, em granja avícola, em Pelotas, $R S$. 2001. 110f. Tese (Doutorado em Entomologia) Universidade Federal do Paraná, Curitiba, PR.

BRUNO, T.V.; J.H. GUIMARÃES, J.H.; SANTOS, A.M. et al. Moscas sinantrópicas (Díptera) e seus predadores que se criam em esterco de aves poedeiras confinadas, no Estado de São Paulo, Brasil. Rev. Bras. Entomol., v.37, p.577-590, 1993.

FRANCISCO, O. Alphitobius diaperinus (Panzer) (Coleoptera: Tenebrionidae) associado a esterco em granjas de aves poedeiras: fenologia, estrutura etária e parasitismo. 1996. 116f. Dissertação (Mestrado em Entomologia) Universidade Estadual de Campinas, Campinas, SP.

GEETHA BAI, M.; SANKARAN, T. Parasites, predators and other arthropods associated with Musca domestica and other flies breeding in bovine manure. Entomophaga, v.22, p.163-167, 1977.

GIANIZELLA, S.L.; PRADO, A.P. Levantamento e sazonalidade de coleópteros (Histeridae) em criação de aves poedeiras. An. Soc. Entomol. Bras., v.27, p.551-555, 1998.

GIANIZELLA, S.L. Observação em laboratório de ciclos biológicos e hábitos de duas espécies de Histeridae (Coleoptera): Euspilotus modestus (Erichson) e Carcinops troglodites Paykull e sua 
possível utilização no controle biológico de dipteros sinantrópicos em granja de aves poedeiras. 2000. 136f. Tese (Doutorado em Entomologia) - Universidade Estadual de Campinas, Campinas, SP.

LEGNER, E.F.; OLTON, G.S. Worlwide survey and comparison of adult predator and scavenger insect populations associated with domestic animal manure where livestock is artificially congregates. Hilgardia, v.40, p. 225-266, 1970.

MARICONI, F.A.M.; GUIMARÃES, J.H.G.; BERTI FILHO, E. A mosca doméstica e algumas outras moscas nocivas. Piracicaba, SP: Fundação de Estudos Agrários Luiz de Queiroz, 1999. $135 \mathrm{p}$.
SAFRIT, R.D.; AXTELL, R.C. Evaluations of sampling methods for darkling beetles (Alphitobius diaperinus) in the litter of turkey and broiler houses. Poult. Sci., v.63, p.23682375, 1984.

ZONTA, E.P.; MACHADO, A.A. SANEST: Sistema de análise estatística para microcomputadores. Pelotas, RS: Universidade Federal de Pelotas, 1984. 75p. (Registrado na Secretaria Especial de Informática sob n ${ }^{\circ} .066060$ - categoria A). 